Revue

Revue de l'histoire des religions

del'histoire

des religions

1 | 2018

Varia

Guy JAROUSSEAU, Églises, évêques et prince à Angers du $V^{e}$ au début $d u X^{e}$ siècle, préface d'Olivier GUILLOT Limoges, PULIM, (« Cahiers de l'Institut d'Anthropologie Juridique », 42), 2015

Bruno Saint-Sorny

\title{
OpenEdition
}

Journals

Édition électronique

URL : http://journals.openedition.org/rhr/8863

DOI : 10.4000/rhr.8863

ISSN : $2105-2573$

Éditeur

Armand Colin

Édition imprimée

Date de publication : 1 mars 2018

Pagination : 160-163

ISBN : 978-2-200-93166-7

ISSN : 0035-1423

Référence électronique

Bruno Saint-Sorny, «Guy Jarousseau, Églises, évêques et prince à Angers du ve au début du xi siècle, préface d'Olivier Guılıot », Revue de l'histoire des religions [En ligne], 1 | 2018, mis en ligne le 20 mars 2018, consulté le 15 janvier 2021. URL : http://journals.openedition.org/rhr/8863 ; DOI : https:// doi.org/10.4000/rhr.8863

Ce document a été généré automatiquement le 15 janvier 2021.

Tous droits réservés 


\section{Guy JAROUSSEAU, Églises, évêques et prince à Angers du ve au début du $\mathrm{XI}^{e}$ siècle, préface d'Olivier GUILLOT}

Limoges, PULIM, («Cahiers de l'Institut d'Anthropologie Juridique », 42), 2015

\section{Bruno Saint-Sorny}

\section{RÉFÉRENCE}

Guy JAROUSSEAU, Églises, évêques et prince à Angers $d u v^{e}$ au début du XI siècle, préface d'Olivier Guillot, Limoges, PULIM, (« Cahiers de l'Institut d'Anthropologie Juridique », 42), 2015, 24 cm, 485 p., $30 €$, ISBN 978-2-84287-665-4.

1 Cette version remaniée d'une thèse de doctorat (Sorbonne, 2005) couvre la période qui va du 4 octobre 453 (ordination de Thalasius connue par la collection canonique d'Angers) à la mort de l'évêque Renaud le 12 juin 1005. Pour la plupart des diocèses, la documentation est tellement lacunaire sur le Haut Moyen Âge qu'il semble impossible d'y consacrer une thèse comparable ; pour d'autres, très rares (l'on pense à Reims et à Tours), elle est au contraire si pléthorique que les historiens tendent à se restreindre à un point particulier (ainsi Jean Devisse au seul archevêque Hincmar de Reims, ou Michel Sot à Flodoard, ou encore Luce Piétri au Tours tardo-antique). Angers offre à l'auteur un poste d'observation permettant d'étudier sur cinq siècles la vie religieuse et spirituelle des églises mais aussi leur insertion et leur rôle dans les institutions politiques du temps.

2 L'étude se développe en trois parties intitulées «L'église de l'évêque saint Aubin et la cité d'Angers V $\mathrm{e}^{\mathrm{e}} \mathrm{VII}{ }^{\mathrm{e}}$ siècle ", "Les liens des princes carolingiens avec Saint-Aubin et les évêques d'Angers de 741 à 880 ", «Évêques d'Angers et princeps (880-1005) ». Les dixhuit annexes qui suivent sont dans l'ensemble bien venues, on se demande seulement 
pourquoi la neuvième (tableau des consécrations des évêques d'Angers avec dates et lieux) n'a pas été rapprochée de la première (liste des évêques d'Angers).

L'auteur traite de son sujet pour ainsi dire au fil de ses sources, se fondant sur toutes celles qu'il pouvait mobiliser : non seulement les sources écrites traditionnellement utilisées par les historiens (sources normatives, diplomatiques, historiographiques), mais aussi des catégories de sources écrites qu'un positivisme historique étriqué avait la mauvaise habitude de négliger (sources hagiographiques, liturgiques), ainsi que les apports les plus récents de l'archéologie. Les sources écrites sont largement citées et traduites, parfois avec une trop grande fidélité à la ponctuation, allemande, de l'édition. L'on pourrait également reprocher à l'auteur une trop grande sécheresse de style: introductions et conclusions des trois parties tiennent chacune en une page; celles des divers chapitres font rarement plus d'une quinzaine de lignes, parfois seulement trois. Autrement dit, l'auteur ne cherche pas à problématiser son propos.

Nous nous attachons ici avant tout au thème des fondements religieux du pouvoir politique. C'est là une perspective historique récemment explorée par Yann Berthelet pour l'antiquité romaine (Gouverner avec les dieux, 2015). Dans ses travaux, Olivier Guillot a depuis longtemps montré que les concepts clefs des institutions romaines, auctoritas et potestas, princeps, sous-tendent toujours celles du monde franc. Dans une réponse à Michel Parisse, qui pensait que «l'on reçoit généralement l'abbatiat à cause d'un titre comtal ou ducal, et non l'inverse ", il avait notamment montré que c'était au contraire « le don royal de l'abbatiat [...] qui fondait en droit la prétention au duché » (Il Secolo di ferro : mito e realtà del secolo X (Spoleto 19-25 aprile 1990), Spolète, 1991, p. 119-121). Jean-Pierre Brunterc'h a précisé et illustré le propos avec le principat aquitain, fondé sur la patrimonialisation de l'abbatiat de Saint-Julien de Brioude, à la fois principal sanctuaire de pèlerinage d'Aquitaine et seul lieu de sépulture, dans le monde franc, d'un empereur romain, ce qui en fait aussi un lieu de mémoire politique (Pays de Loire et Aquitaine de Robert le Fort aux premiers Capétiens, éd. O. Guillot et Robert Favreau, Poitiers, 1997, p. 69-116). La thèse de Guy Jarousseau nous semble donner les éléments permettant de confirmer que le contrôle de l'abbatiat le plus prestigieux (à la fois spirituellement et politiquement) d'un regnum fut ce qui servit à certains aristocrates de tremplin vers le principat en leur apportant ce charisme religieux qu'est l'auctoritas.

5 La basilique de Saint-Aubin fut fondée dès avant 558 par la volonté et l'imperium du roi Childebert $\mathrm{I}^{\mathrm{er}}$ (selon la charte de l'évêque Néfingue de 972) à $220 \mathrm{~m}$ au sud-est de la Cité, sur la voie de Tours qui était peut-être celle de l'adventus royal à Angers. L'on devine là la vocation politique de Saint-Aubin, dont Jarousseau montre la précocité : la formule d'Angers $n^{\circ} 50$ (vers 578/579) relative au jugement de l'homicide indique que le serment purgatoire permettant à l'accusé de se mettre hors de cause doit avoir lieu in ecclesia seniore/seniores loci le $1^{\mathrm{er}}$ mars, c'est-à-dire le jour de la Saint-Aubin, suggérant que l'église en question doit être la nouvelle basilique, qui se trouve ainsi fortement associée à la haute justice royale. Et l'auteur de souligner que Childebert est le seul roi mérovingien à avoir été comparé à Melchisédech, roi-prêtre de justice et de paix.

Il observe aussi que ce roi est le premier, avant même Clotaire II et son fameux édit de 614, à avoir prescrit (par le concile d'Orléans de 549) que dans la procédure d'accession à l'épiscopat la consécration épiscopale ne saurait être valide si elle n'est précédée de l'investiture royale. Or, à Angers, cette consécration semble bien avoir lieu dès ce moment-là non plus à la cathédrale, mais à Saint-Aubin, pratique attestée à la fin du siècle à Auxerre où Aunaire est consacré à Saint-Germain et non dans la cathédrale - 
l'on pourrait sans doute remarquer également que l'évêque de Rome est intronisé au Latran mais consacré au Vatican.

7 La basilique de Saint-Aubin est donc d'emblée non seulement un lieu de dévotion spirituelle, mais un haut lieu du pouvoir royal. Elle a un abbé-clerc et un patrimoine propres (mais toujours sous tutelle épiscopale) attestés dès 616, puis un abbé-moine, Niulfe, dirigeant une communauté cénobitique selon une norma qui est probablement la règle mixte composée par l'abbé Walbert de Luxeuil et que la reine Bathilde, pendant sa régence (650/654), fait adopter par les seniores basilicae du royaume en échange du privilège de l'immunité, ces basiliques devenant ainsi des monastères très autonomes vis-à-vis de leurs évêques tant sur le plan religieux que sur le plan patrimonial, et exerçant de facto la potestas (c'est-à-dire le pouvoir politique) sur leurs membres et leurs dépendants.

8 Sous Charlemagne apparait l'abbatiat laïc : l'abbé est un grand laïc, le «magnifique recteur Gontier » («magnifique » est depuis le Bas-Empire l'épithète officielle d'un dignitaire laïc de très haut rang), à la tête d'une communauté de chanoines et non plus de moines, suivant probablement la règle de saint Chrodegang et non plus la règle mixte. Louis le Pieux investit abbé son chancelier, Hélisachar : également abbé de SaintRiquier à partir de 822 environ, c'est lui qui introduit la séparation des deux menses (ce qui est assez précoce) dans les deux abbayes.

9 Ce caractère politique, et non seulement spirituel, de Saint-Aubin se remarque également à travers le séjour de l'empereur Louis le Pieux en 818, dans la perspective d'une ample expédition militaire contre les Bretons à laquelle les principales églises de Neustrie doivent contribuer. C'est à Saint-Aubin que Théodulphe, évêque d'Orléans déposé pour rébellion en avril 818, est assigné à résidence, où il compose entre 819 et 821 l'hymne liturgique Gloria laus, dont Guy Jarousseau confirme l'authenticité.

$10 \mathrm{Au}$ tournant $\mathrm{du} \mathrm{IX}{ }^{\mathrm{e}} \mathrm{s} . \mathrm{x}^{\mathrm{e}}$ siècle, les institutions du royaume de Francie occidentale connaissent un profond changement, non pas avec la prétendue institutionnalisation de la féodalité qui serait consécutive au capitulaire de Quierzy de 877 (vieille lune de l'historiographie qui remonte à Montesquieu et que l'on s'étonne de trouver encore aujourd'hui dans des manuels d'histoire des institutions, voire sous la plume de médiévistes réputés), mais ce que nous appellerons la mutation princière: ce phénomène, caractérisé par la multiplication des princes dans le même royaume et une hiérarchisation entre eux, dénote une redéfinition de ce terme si l'on se souvient qu'à l'origine le «prin-ceps » désignait celui qui «tient la première » place, ce qui supposait qu'il n'y en eût qu'un seul dans un pays donné.

11 En Anjou, c'est Foulque le Roux, vicomte ou comte mineur (tel est le sens de comes juvenis dans une charte de 929) d'Angers, qui après avoir perdu le comté de Nantes (détenu de 906/909 à 919) fonde la destinée de sa famille grâce à l'abbatiat laïc de SaintAubin, sous l'autorité d'Hugues le Grand qui le fait finalement comte de plein exercice quand il devient lui-même duc des Francs. Nous dirions, plus nettement que l'auteur, que l'abbatiat de ce monastère si politique, une fois détenu à titre héréditaire, assure au comte l'auctoritas et le qualifie ainsi pour le principat. Ainsi, tel fief constitué en 969 aux dépens du patrimoine de la cathédrale Saint-Maurice pour un fidèle du comte sur le modèle carolingien de la "précaire au nom du roi ", nous semble davantage un effet de l'auctoritas du princeps qu'est le comte d'Anjou depuis 956/958 qu'une «retombée possible du pouvoir du comte en tant qu'abbé de Saint-Aubin lors de la succession épiscopale » (p. 304). 

canoniques et institutionnels de Saint-Aubin qui font d'elle, avant même la cathédrale, la principale église d'Anjou, qu'en 964/966 le princeps Geoffroy Grisegonelle a réformée en introduisant la règle bénédictine et en poussant son frère Gui à abandonner l'abbatiat pour investir un abbé-moine, le comte conservant le droit d'investiture à l'abbatiat, avec à deux reprises quelques aménagements sans grande conséquence. Ainsi donc Saint-Aubin semble bien avoir joué pour le principat angevin un rôle analogue à celui de Saint-Julien de Brioude pour le principat aquitain. Il faudrait alors voir dans quelle mesure l'on pourrait appliquer ce paradigme aux autres principautés naissant au $\mathrm{x}^{\mathrm{e}}$ s., voire aux Robertiens/Capétiens. La nouvelle dynastie ne doit-elle pas son nom au fait qu'Hugues Capet (et déjà son père parfois surnommé ainsi lui aussi) portait la chape de saint Martin (l'une des origines du manteau bleu du sacre) parce qu'il était abbé laïc de Saint-Martin de Tours, ce que les rois sont d'ailleurs restés jusqu'à la fin de l'Ancien Régime?

\section{AUTEURS}

\section{BRUNO SAINT-SORNY}

Institut catholique de Rennes. 